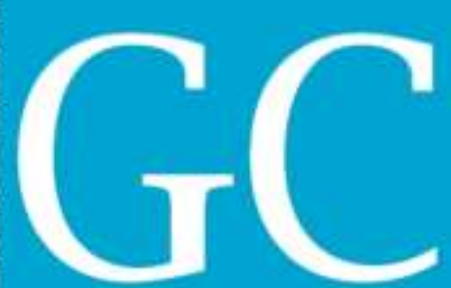

\title{
A Igreja de Nossa Senhora do Rosário dos Homens Pretos e o espaço urbano negro na cidade de São Paulo pós-abolição.
}

The Church of Our Lady of the Rosary of Black Men and the black urban space in the city of Sao Paulo post-abolition.

La Iglesia de Nuestra Señora del Rosario de los Hombres Negros y el espacio urbano negro en la ciudad de Sao Paulo después de la abolición

\section{Fabrício Forganes Santos}

Mestrando FAAC/UNESP, Brasil. fabricio.forg@gmail.com

Nilson Ghirardello Professor Doutor, FAAC/UNESP, Brasil. nilson.ghirardello@unesp.br 



\section{Revista Nacional de}

Gerenciamento de Cidades

\section{INTRODUÇÃO}

A Igreja no Brasil, sob o regime do padroado, assim como em outras colônias portuguesas, estaria intimamente ligada ao Estado apoiando a introdução da mão-de-obra escrava negra e incutindo nos "gentios" os dogmas cristãos. Contudo, a maneira como se deu e formalizou a união da Mitra com a Coroa, para além das responsabilidades espirituais, seria expressa, também, na ordenação urbanística de nossas cidades (MARX, 1989, p.21), o que possibilita a investigação de um grupo particular no contexto colonial - no caso deste trabalho, africanos e afrodescentes escravizados ou livres - através do edifício destinado as suas práticas católicas. Sendo assim, a presença negra nos centros urbanos das cidades brasileiras pode ser analisada a partir da história das igrejas de suas irmandades leigas.

Para além das necessidades inerentes ao ciclo do nascimento a morte, aspectos imprescindíveis na doutrina e na prática católica, as irmandades religiosas foram associações que deram ao negro a possibilidade de camuflar práticas ancestrais nas diferentes formas de cumprir a ritualística católica. Tal aspecto corroborou para a preservação da identidade negra, acobertando inclusive a memória religiosa africana na diáspora (TERRA, 1984, p. 247). Sendo este um lugar privilegiado onde seria possível a salvaguarda da cultura e o resgate das tradições ancestrais, ao redor das igrejas destas irmandades estariam também as casas dos alforriados ou esconderijos de escravos foragidos, favorecendo tais espaços como lugares de convivência, pequenos enclaves urbanos negros que rompiam a uniformidade da paisagem citadina colonial.

Nas cidades brasileiras, a permanência destes lugares estaria intrinsicamente ligada as relações de poder entre a classe dominante e os subalternos, territórios que entrariam em xeque a partir de 1888. Ainda que em outras épocas tal grupo já revelasse sua repulsa a população negra, a elite nos anos que seguiram a abolição se apropriaria dos termos "higienização" e "modernização" para justificar a expropriação dos terrenos onde se localizavam as igrejas dos negros e seu patrimônio, cumprindo os desejos de uma sociedade republicana em apagar seu passado colonial.

As transformações ocorridas na Igreja de Nossa Senhora do Rosário dos Homens Pretos de São Paulo, nas ruas e largo do entorno, ainda que não identifiquem claramente os agentes, confirmam tal hipótese ao revelar as tentativas de enfraquecimento deste grupo e ações que ocasionaram o apagamento momentâneo da presença negra das regiões privilegiadas do urbanismo paulistano.

\section{METODOLOGIA E OBJETIVOS DESTE TRABALHO}

Utilizando como metodologia a revisão bibliográfica e a pesquisa arquivística em documentos primários, textuais e iconográficos produzidos ou elencados por retratar a Igreja de Nossa Senhora do Rosário dos Homens Pretos e seu entorno no arco temporal de 1870 a 1908, o presente trabalho tem por objetivo destacar a presença dos negros no processo de 


\section{Revista Nacional de}

Gerenciamento de Cidades

urbanização paulistano a partir das igrejas das irmandades negras - compostas exclusivamente por leigos -, revelando os conflitos, as ações de apagamento e tentativas de expropriação do patrimônio das irmandades negras, em particular deste templo localizado na cidade de São Paulo.

\section{IRMANDADE DE NOSSA SENHORA DO ROSÁRIO DOS HOMENS PRETOS EM SÃO PAULO}

Em se tratando de um grupo que teve sua inserção aliada as temporalidades econômicas, a relevância dos lugares das igrejas das irmandades dos homens pretos em determinado contexto social se dará a partir do número de negros que viviam em tais núcleos urbanos. No caso de São Paulo, as condições geográficas e o meio ambiente que a Vila de Piratininga apresentava não favoreceram as atividades dos primeiros ciclos econômicos, ocasionando o distanciamento da metrópole e o seu isolamento por quase dois séculos. O posicionamento longe da costa e da pujança da economia nordestina, tornaria a vila pouco relevante no período colonial, obrigando os paulistas a desempenharem um papel economicamente secundário a partir da tímida economia de subsistência baseada no uso da mão-de-obra indígena (LUNA, 2009, p. 163). Ainda que no final do século XVIII com a descoberta do ouro nas Minas Gerais a região fornecesse gêneros alimentícios e utensílios para abastecer as cidades e povoados mineiros, ou mesmo houvesse atividades mineradoras em locais próximos ${ }^{1}$, não foram suficientes para impulsionar a economia paulista e nem favorecer a presença de um contingente considerável de escravos negros. Contudo, há indícios de que a temporalidade do ouro criou um fluxo intenso de importação de africanos para a colônia, abastecendo também o mercado paulista (LUNA, 2009, p. 164), o que contribuiria para o destaque na cena urbana negra no século XIX.

Os poucos negros que estiveram na cidade nos primeiros séculos trabalhavam principalmente em serviços domésticos e atividades agrícolas, atendendo aos religiosos e a sociedade civil. Contudo, embora esta população em São Paulo fosse menor quando comparada com os números dos africanos ou afrodescentes em outras capitais de provincias brasileiras, ela ainda teria peso e presença relevante, fato que pode ser comprovado a partir da existência de uma irmandade de negros católicos na cidade já no primeiro quartel do século XVIII; documentos estudados pelo padre Leonardo Arroyo e revelados na obra "Igrejas de São Paulo" publicada em 1954, podem ser indícios da gênese da organização dos negros em São Paulo ao redor de um orago católico. Ao citar a igreja dos pretos, Arroyo revela que em 1721 os membros da Irmandade de Nossa Senhora do Rosário dos Homens Pretos enviaram uma representação ao rei de Portugal, implorando permissão para "edificar um templo em que pudessem solenizar os mistérios do Rosário da Mãe de Deus". Ainda no mesmo ano, segundo este autor, tal confraria

\footnotetext{
${ }^{1}$ De acordo com o Professor Nestor Goulart, entre 1600 e 1820 foram produzidos na província de São Paulo um total de 4.650 arrobas de ouro, exploradas em mais de 150 minas descobertas a partir do século XVI. Nas jazidas localizadas próximas dos aldeamentos de Embu-Guaçu, Guarulhos, Itapecerica da Serra, Mogi das Cruzes, a mão de obra utilizada era a indígena, que recebia como moeda de troca por seus trabalhos facas, anzóis, machados e utensílios domésticos e outros objetos úteis para a vida em suas tribos. (REIS, 2013)
} 


\section{Revista Nacional de}

Gerenciamento de Cidades

Após a elevação de São Paulo a categoria de cidade, a partir do segundo quartel do século XVIII as igrejas deste lugar tiveram a independência da Arquidiocese da Bahia, momento da criação do Bispado de São Paulo e origem da contenda entre a igreja paulista e os negros. O primeiro bispo, Dom Bernardo Rodrigues Nogueira, já em 1750 apoiava as investidas do governador Luís Mascarenhas contra os quilombos existentes nas proximidades de São Paulo, estando de acordo também com outras medidas que a sociedade tomava contra os negros como a proibição das danças e a cobrança de Rs 0 \$320 réis como pagamento dos escravos aos párocos na encomendação de defuntos (SOUZA, 2004, p.162). Concorrendo com as deliberações eclesiásticas, a Câmara Municipal tomaria medidas contra os negros no início do século XIX, restringindo o direito de circulação no espaço urbano através de leis ou resoluções que versavam sobre a proibição de estar na rua à noite no ano de 1832, e do exercício da capoeira em praças, ruas ou casas públicas em 1833 (MARX, 1989, p. 99-100), restando aos "malungos"“4 a realização de suas festas e de suas cerimonias de forma secreta.

As discussões acerca da população negra no decorrer do século XIX, em parte, se devem ao aumento considerável de escravos que passaram a perambular na urbe paulistana, decorrente principalmente dos investimentos aplicados a cultura cafeeira. O cultivo do café, que começou timidamente em meados do século XVIII na região Norte, teve o seu auge no século XIX, posicionando São Paulo como uma cidade importante, que passaria a ser densamente povoada neste momento, pela localização privilegiada entre o litoral e o interior. Abastecida pela produção das localidades essencialmente agrícolas que a cercavam, a cidade viu a quantidade de negros duplicar ao longo do século XIX, parte deste contingente de escravos migrados de outras partes do país. Entre os anos de 1766 e 1769, de acordo com correspondências de Morgado de Mateus, a soma de escravos era de 23 mil negros e 3 mil indígenas, o que totalizava $26 \%$ dos habitantes de São Paulo (LUNA, 2009, p. 168). Em 1803, de acordo com os maços de população, a quantidade de negros na cidade seria estimada em 36 mil pessoas, sendo $44 \%$ o número de escravos não sendo identificada a presença de indígenas (LUNA, 2009, p. 168).

A população de São Paulo, com o sucesso da temporalidade do café, cresceria consideravelmente chegando a percentuais de $124,78 \%$ nos anos de 1872 e 1890 (SANTOS, 2017 , p. 33). Tal patamar contribuiria também para o aumento de negros circulando na cidade de São Paulo - que as vésperas da Abolição se configurava como a capital de uma das três maiores províncias escravistas do Império (LUNA, 2009, p. 307) - e principalmente, perambulando no entorno da Igreja do Rosário ou aderindo a irmandade negra aí estabelecida. Como consequência, outras duas irmandades negras seriam fundadas na cidade, a primeira por volta de 1755, com a autorização em 1802 para a ereção da capela dos irmãos da Irmandade de Nossa Senhora do Rosário dos Pretos da Penha de França, localizada em importante freguesia de São Paulo situada no caminho que ligava a cidade às Minas Gerais ${ }^{5}$, e

\footnotetext{
${ }^{4}$ Termo utilizado pelos negros bantos para designar outro africano da irmandade.

${ }^{5} \mathrm{O}$ auto de ereção datado de 16 de junho de 1802 encontra-se no Livro de Patrimônio $002-01.02 .003$. P. 214. no Arquivo Metropolitano de São Paulo. O livro de Assentamentos dos Irmãos de Nossa Senhora do Rosário da Penha
} 


\section{Revista Nacional de}

Gerenciamento de Cidades

Além da ampliação de patrimônio constituído de imóveis, o final do século XIX possibilitaria ajustes da arquitetura do templo católico como revelam as fotografias de $1862 \mathrm{em}$ comparação a de 1900 , demonstrando a preocupação dos malungos em atualizar os modelos estilísticos da igreja. Na fachada principal o frontão perderia seu acabamento escalonado (figura 1) para curvas sinuosas (figura 3), e haveria também a substituição dos caixilhos das janelas. No interior, é provável que já estivesse finalizado o douramento do altar, paramentado com damascos conforme intenção do consistório da irmandade em carta endereçada a Câmara Municipal na data de 11 de junho de $1872 .{ }^{6}$ Fora do templo, o largo da igreja e a Rua do Rosário permaneciam constantemente lugares de reunião de negros, fato que chamaria a atenção do poder legislativo e da elite paulistana para a tomada de decisões que colocariam em xeque este núcleo urbano no início do século XX.

\section{RESULTADOS: URBANISMO NEGRO NO TRIANGULO HISTÓRICO DA SÃO PAULO IMPERIAL}

A cidade de São Paulo por muitos anos preservaria suas características coloniais dedicando certo destaque aos templos católicos. Tal aspecto pode ser comprovado a partir do relato de Carl von Koseritz que visitou a cidade em 1883:

"A cidade que é das mais velhas do Brasil, tem o aspecto de todas as velhas cidades. Na parte mais antiga as ruas são estreitas, tortuosas, ligadas em todas as direções e interrompidas por uma quantidade de praças pequenas e irregulares, como por exemplo as da Sé e Sete de Setembro, a Praça Municipal e o Largo do Rosário e mesmo o Largo de São Bento. Há becos que não tem mais de 20 ou 30 passos de comprimento, pois casas ou igrejas levantadas no meio da rua a dividem em dois becos. [...] Com meu amor pelas velharias, a antiga cidade me pareceu mais amável, ainda que possua demasiado número de igrejas, coisa chocante para um homem pouco habituado com elas."

(BRUNO, 1981, p. 94)

Tal constatação plausível justificava-se porque o traçado urbano de São Paulo, assim como o de outras cidades brasileiras, seria orientado de acordo com as decisões eclesiásticas das Constituições Primeiras do Arcebispado da Bahia, de 1707, que elencaria os pontos de destaque no panorama das cidades, realizando a ligação entre eles de acordo com seus critérios. Os templos católicos seriam implantados no ponto alto de uma rua ou de um setor, em "lugar decente, livre de humidade [...] em distância em que se possão andar as Procissões ao redor dellas", conforme estabelecido no Título XVII do livro Quarto escrito por D. Sebastião Vide. ${ }^{7}$ Assim como para as demais igrejas, ao clero também estariam condicionadas as capelas ou igrejas das irmandades dos homens pretos, cuja implantação e arquitetura não deveriam

\footnotetext{
${ }^{6}$ Documento Fundo CMSP. Grupo Conselho de Vereadores. Série Correspondência de Instituição Religiosa. Assunto: Desapropriação de terreno da irmandade e tendo poucos recursos e pretendendo realizar obras na igreja solicita da "C.M." o mesmo lageado. Data 1872. Arquivo Histórico Municipal de São Paulo

${ }^{7}$ O clero se configurou como detentor dos interesses urbanos até o final do período imperial. (MARX, 1989, p. 75)
} 


\section{Revista Nacional de}

Gerenciamento de Cidades

frente do templo católico dos pretos (QUINTÃO, 2002, p.63) e alinhamento da Rua do Rosário. Subsequente a esta ação, com a implantação das linhas de bonde, a Igreja do Rosário seria citada como possível lugar que deveria desaparecer em detrimento às melhorias urbanas, considerando neste caso a desapropriação da igreja como um ato de utilidade pública. Não sendo possível a demolição do templo católico naquele momento, as reformas acometeram os bens imóveis da Irmandade para o novo alinhamento da rua (no ano de 1861), e consequentemente os lugares de reunião dos negros católicos, expropriados para os desvios da linha de bonde em 1879 e desvalorizados com a remoção do chafariz do Rosário no ano de $1887^{9}$. Somado aos interesses do governo local, as novas diretrizes do Concilio Vaticano I (1869-1870) teriam seus ecos no Bispado de São Paulo que apoiaria tal medida objetivando o enfraquecimento das irmandades dos negros leigos; a documentação das tratativas de expropriação do terreno da irmandade negra cita um suposto encontro entre os vereadores e o bispo ${ }^{10}$.

A expulsão das irmandades dos negros das regiões privilegiadas teria como um dos argumentos atender aos padrões de higienização propostos para São Paulo, do final do século $\mathrm{XIX}$, que assim como outras cidades brasileiras planejava intervenções consideráveis no traçado urbano na expectativa de eliminar o passado colonial e trazer a modernidade; os mapas produzidos por desenhistas na década de 1890 manifestam os interesses imobiliários aplicados as igrejas das irmandades negras, ora identificadas e ora apagadas na cartografia. ${ }^{11}$ (figura 4). Havia um desejo de que a população paulistana fosse branca e de origem européia, principalmente por parte dos grupos ligados aos governos da cidade, não havendo espaço para a população negra principalmente a partir dos anos pós-abolição.

\footnotetext{
${ }^{9}$ Conforme anais da Câmara Municipal. Arquivo da Câmara Municipal de São Paulo.

${ }^{10}$ Folha avulsa com data de 10 de setembro de 1903. Volume 1988. Lei $n^{\circ}$ 698. Arquivo Histórico Municipal de São Paulo.

${ }^{11}$ Do total das plantas estudadas até o momento, nas elaboradas na década de 1890 a Igreja de Nossa Senhora do Rosário dos Homens Pretos, ainda que presente fisicamente em seu local original, foi apagada. A ação acontece nas seguintes plantas: Planta da Capital do Estado de S. Paulo e seus arrabaldes - Jules Martin, 1890 e Nova Planta da Cidade de São Paulo - U. Bonvincini e V. Dubugras, 1891. Tais mapas encontram-se na reserva técnica dos seguintes museus: Museu Afro Brasil e Coleção Brasiliana do Itaú Cultural.
} 


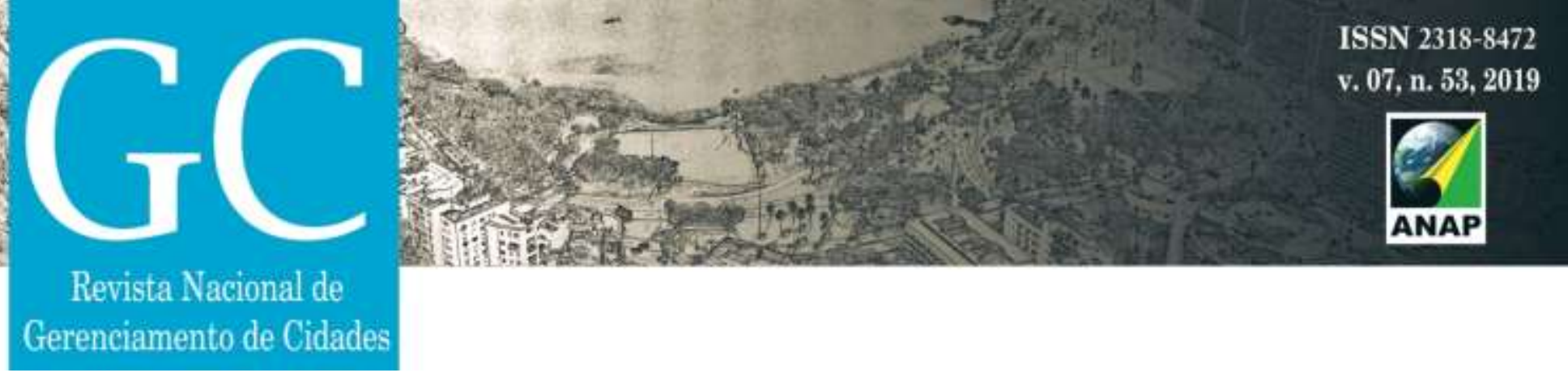

Figura 4. Nova Planta da Cidade de São Paulo - U. Bonvincini e V. Dubugras, 1891. Detalhe da planta onde deveria estar a Igreja dos Pretos.

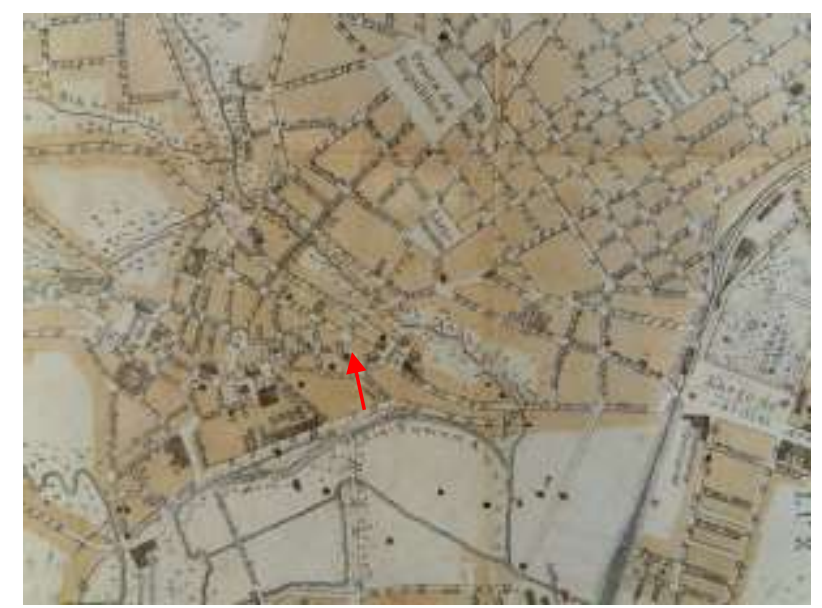

Fonte: Acervo Itaú Cultural Coleção Brasiliana

A irmandade dos homens pretos cuja igreja se localizava próximo ao centro da cidade seria ressarcida com certa quantia e o projeto arquitetônico do novo templo a ser construído no Largo do Paissandu. Todavia a investigação na documentação anexada à Lei n ${ }^{\circ} 698$ de 24 de dezembro de 1903 comprova a rejeição da população que vivia nos arredores do largo do Paissandu à presença dos negros católicos neste lugar, gerando um abaixo-assinado e a indicação de três terrenos ${ }^{12}$ para a implantação da igreja dos pretos, destinando o largo para o uso público. Tal rejeição, contudo, não teve boa recepção por parte da prefeito e dos vereadores, o primeiro porque não queria investir mais dinheiro na construção do templo católico, e o segundo grupo por achar que a igreja poderia ser retirada do largo a qualquer tempo, nas palavras do Dr. Correa Dias: "Dirão que a egreja dali não sahirá mais... ora, ninguém pensava que a egreja do Collegio sahisse do logar em que estava: alguém pensava que o templo que antigamente existiu no largo do Ouvidor fosse dali retirado? Os templos e os prédios são transitórios, enquanto houver mundo ha de haver município."13 A memória dos negros do triangulo histórico seria apagada no ano de 1904, com a substituição da designação Largo do Rosário para Praça Antônio Prado ${ }^{14}$, e a construção da nova igreja segundo os padrões arquitetônicos ecléticos do início do século XX. (figura 5)

\footnotetext{
${ }^{12} \mathrm{O}$ primeiro sito a Rua Coronel Xavier de Toledo, $\mathrm{n}^{\circ} \mathrm{s} 3$ e 5. Conforme carta de 31 de outubro de 1903 . Um segundo terreno faceando o Largo do Arouche, entre as Ruas Arouche e Bento Freitas. Conforme Carta de 4 de novembro de 1903. O terceiro lote na esquina das Ruas São João e Conselheiro Crispiniano. Conforme Carta de 6 de novembro de 1903. Lei $n^{\circ}$ 698. Volume 1988. Arquivo Histórico Municipal de São Paulo.

${ }^{13} 48$ a Sessão Ordinária realizada em 19-12-1903. P. 438. Anais da Câmara Municipal de São Paulo.

${ }^{14}$ Lei $n^{\circ} 799$ de 24 de dezembro de 1904. Volume 1988. Arquivo Histórico Municipal de São Paulo.
} 


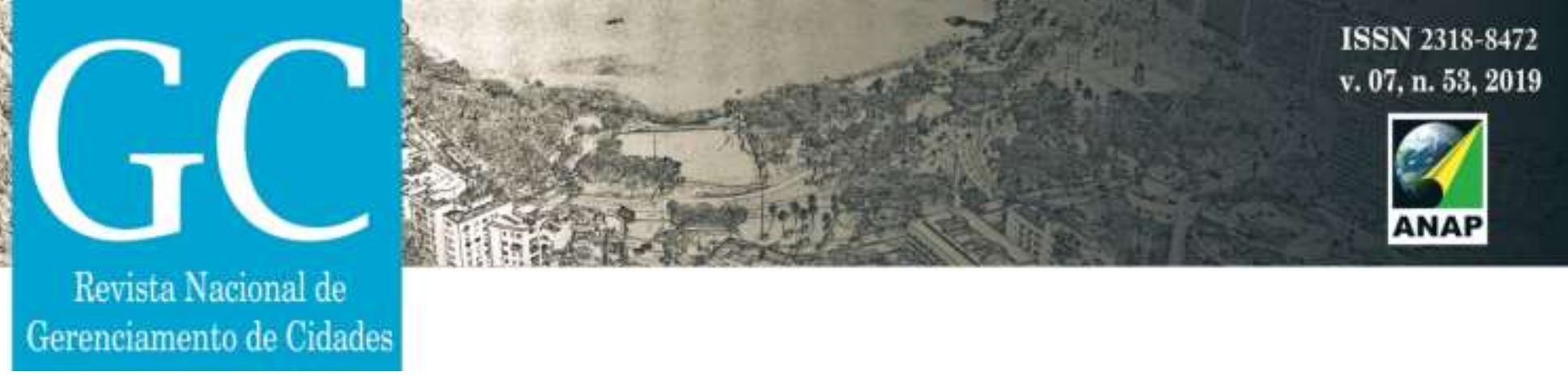

Figura 5 Largo do Paissandu e Igreja de N.S. do Rosário dos Pretos. Aurélio Becherini. 1953

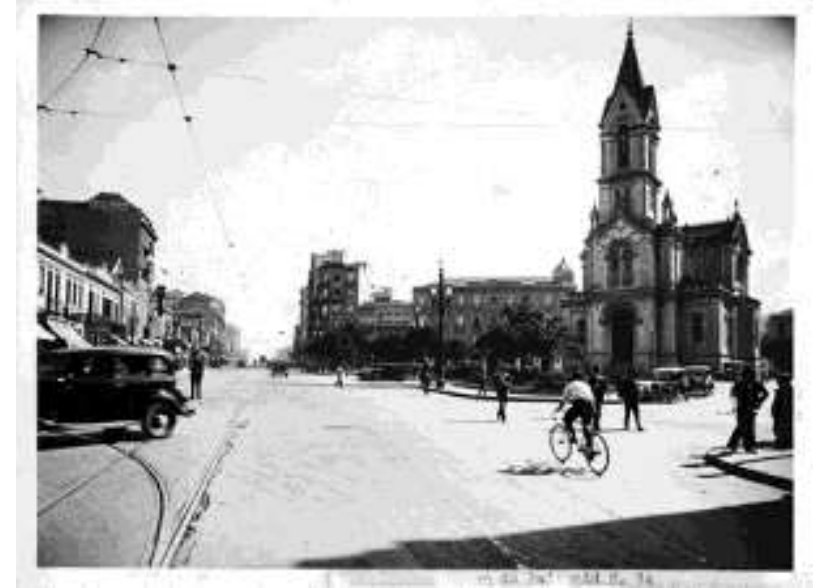

Fonte: http://www.saopauloinfoco.com.br/largo-do-paissandu/

\section{CONSIDERAÇÕES FINAIS: NEGRAS CICATRIZES URBANAS}

A cidade de São Paulo também se firmou como um importante lugar abolicionista, ainda que os números de trabalhadores livres superassem o de escravos (COSTA, 2010, p. 36). Os debates e as estratégias acerca da liberdade dos negros escravos permearam muitos dos lugares católicos, como a Igreja de Nossa Senhora dos Remédios (COSTA, 2010, p. 112), a Igreja de Nossa Senhora da Boa Morte e certamente o templo dedicado a virgem do Rosário e as casas que faziam parte do patrimônio desta irmandade, utilizadas algumas vezes como esconderijo para negros foragidos. Abolida a escravatura, em contrapartida as igrejas construídas para atividades das irmandades negras, estes templos ainda preservariam suas características de culto por algum tempo, não sofrendo danos nas primeiras décadas do século $\mathrm{XX}$.

Anos após a assinatura da Lei Áurea, a irmandade de Santa Efigênia seria extinta, perdendo seu templo construído em taipa de pilão em decorrência de disputas com o vigário José de Camargo Barros no ano de 1905. A nova igreja seria reconstruída no mesmo local com projeto em tipologia neorromânica assinado pelo arquiteto austríaco Johann Lorenz Madein. Em contrapartida, por estar longe da região economicamente mais valorizada, a Igreja de Nossa Senhora do Rosário da Penha de França conseguiria se preservar em sua integridade física, recebendo apenas ajustes na fachada decorada com ornamentos decorativos de acordo com o padrão da época, ou anexos que possibilitavam novos usos ao edifício. Contudo, no tocante às atividades religiosas, a vigilância dos padres Redentoristas, responsáveis por esta igreja desde o ano de 1905, vez ou outra subjugava as formas de culto ou as atividades realizadas pela irmandade, tendo seu orago mudado para São Benedito e suas atividades reduzidas por decisão do clero local. Nas primeiras décadas do século XX, aos malungos paulistanos restava 


\title{
Revista Nacional de
}

Gerenciamento de Cidades

apenas a Igreja do Rosário do largo do Paissandu como elo de ligação com a tradição católica inculturada e como marco da resistência urbana negra.

No que tange a população negra, coube a adaptação a vida como homem livre, resistindo as mazelas do cotidiano imposto pelas autoridades da época. De fato, tal dificuldade já se configurava desde os idos de 1890, quando o então Marechal Deodoro da Fonseca promulgou o Decreto-Lei no 528, de 28 de junho de 1890, que logo em seus primeiros artigos determinava que:

\begin{abstract}
Art. 10 É inteiramente livre a entrada, nos portos da Republica, dos individuos válidos e aptos para o trabalho, que não se acharem sujeitos á acção criminal do seu paiz, exceptuados os indigenas da Asia, ou da Africa que sómente mediante autorização do Congresso Nacional poderão ser admittidos de accordo com as condições que forem então estipuladas.
\end{abstract}

(RIBEIRO, 2016, p.112)

O cenário pós-abolição criava dificuldades na inserção da mão-de-obra negra no mercado de trabalho, fato que pode ser constatado a partir de diversos levantamentos publicados em jornais da época, onde é notória a preferência pelo trabalhador imigrante e o percentual de trabalhadores nacionais não chega a 10\% (SANTOS, 2007, P.48); a esta parcela da população estariam reservados apenas os serviços "informais" como de carroceiros, quitandeiras, vendedores de tabuleiros e outros serviços de ambulantes. (SANTOS, 2007, P. 142). Destituídas da posse dos negros, os negros sofreriam ainda com a elite, que incitaria os governantes a usarem como arma o urbanismo e como estratégia a criação de leis e regulamentos que restringiam o direito a cidade como a proibição de festejos e outras manifestações tradicionais da cultura negra. Houve de certa forma também um descaso por parte dos políticos também para com a saúde do povo negro, chegando a se ignorar os altos índices de mortalidade proporcionados pela doenças que acometeram esses grupos, justificados segundo a elite escravocrata saudosista como consequência do vício da embriaguez. (SANTOS, 2001, P. 44). Como resultado do desamparo ao povo negro, o plano urbano das cidades viu surgir um número considerável de edificações destinadas ao acondicionamento dos criminosos e mendigos (COSTA, 2010, p. 138).

As estratégias de cerceamento da cidade, com o decorrer do século XX, atingiriam novamente o templo católico da única irmandade dos pretos que conseguiria resistir às pressões sociais impostas a comunidade negra. Ainda que a igreja mantivesse sua vocação política como sede de movimentos negros como a "Associação dos Homens Unidos" que ali realizava suas reuniões desde 1917, o prédio sofreria a pressão por novamente se localizar em uma área privilegiada $^{15}$. Em 1940 a Câmara Municipal de São Paulo novamente teria como alvo a Igreja

\footnotetext{
${ }^{15}$ A “Associação dos Homens Unidos” cuja primeira ata de 16 de março de 1917, aparece assinada por mais de 40 pessoas, presentes na inauguração da entidade realizada no consistório da Irmandade do Rosário. Um dos objetivos
} 


\section{Revista Nacional de}

Gerenciamento de Cidades

de Nossa Senhora do Rosário dos Homens Pretos, argumentando a necessidade de reformulação do traçado viário daquele entorno e a opção por implantar no Largo do Paissandu uma estátua do Duque de Caxias - projeto do artista italiano Victor Brecheret vencedor de um concurso público -, projeto urbanístico idealizado na gestão de Prestes Maia (MAIA, 1945,p. 69). As negociações dariam a Irmandade um novo terreno no bairro da Barra Funda, mas em decorrência a inúmeros protestos (RIBEIRO, 2016, p. 120) o projeto foi abortado e então a igreja se manteve neste local. No ano de 1953 o prefeito Jânio Quadros acataria a sugestão de um grupo de políticos da época, criando o concurso para a estátua da Mãe Preta, escultura do artista Júlio Guerra que, embora tenha sofrido críticas na época devido ao custo da obra, foi instalada no Largo do Paissandu na tentativa de recriar uma ambiência com elementos que pudessem reforçar o caráter da praça como lugar de memória da comunidade afro-brasileira. ${ }^{16}$

As ações protecionistas só teriam trariam luz as igrejas das irmandades negras no final do século XX, momento de reconhecimento da participação da população negra na construção da identidade brasileira. Como resultado desta falta de atenção, as irmandades negras perderiam força, decorrente da ação incisiva do clero na expropriação do patrimônio das confrarias negras, da usurpação administrativa destes grupos e da padronização dos cultos e festejos de acordo com a tradição católica romana, afastando a comunidade negra em virtude das diferenças culturais entre os ritos executados pelos leigos e os novos, organizados pelos sacerdotes. A consequência destes atos foi o esvaziamento dos negros destas igrejas e o abandono destes templos.

Embora com passagens díspares, a história urbana de grande parte das igrejas das irmandades negras se entrelaça pelo viés social, justificada principalmente pela cobertura que tais edificações destinava a população marginalizada. "Nenhuma pessoa branca que vive hoje é responsável pela escravidão. Mas todos os brancos vivos hoje colhem os benefícios dela, assim como todos os negros que vivem hoje tem as cicatrizes dela" ${ }^{17}$. Ao relatar as disputas territoriais e as tentativas de apagamento da memória urbana negra no estudo de caso da Igreja de Nossa Senhora do Rosário dos Pretos de São Paulo, propõe-se a construção de uma nova narrativa sobre a relação dos negros com as igrejas católicas e com o urbanismo paulistano, assim contribuindo para a história loca, para o reconhecimento das cicatrizes urbanas e para a atenção com os espaços católicos afro-brasileiros que ainda resistem no plano urbano das nossas cidades.

dessa associação era "congregar todos os homens de cor preta e seus oriundos dando aos mesmos instrucções práticas á vida e facultando-Ihes os meios de ganharem honestamente o pão de cada dia" (RIBEIRO, 2016, p. 121)

16 Conforme Ata da 194a Sessão Ordinária da Câmara Municipal de São Paulo, realizada em 31 de agosto de 1953, disponível no Arquivo da Câmara Municipal de São Paulo.

${ }^{17}$ Frase atribuída ao rapper estadunidense Talib Kweli, retirada de artigo da juíza Fernanda Orsomarzo, do Tribunal de Justiça do Paraná, publicado no Jornal O estado de São Paulo, na data de 9 de setembro de 2019. 


\section{Revista Nacional de}

Gerenciamento de Cidades

BUENO, Beatriz Piccolotto Siqueira. Tecido urbano e mercado imobiliário em São Paulo: metodologia de estudo com base na décima urbana de 1809. Anais do Museu Paulista, V-13, N-1. Ano 2005.

COSTA, Emilia Viotti da. A Abolição. 9 ed. São Paulo: Editora Unesp, 2010

COSTA, Valéria. Religiões Negras no Brasil. Da escravidão à pós-emancipação. / Valeria Costa e Flavio Gomes [Org]. São Paulo: Selo Negro Edições, 2016.

FERREIRA, Abílio. Tebas, um negro arquiteto na São Paulo escravocrata (abordagens). / Abilio Ferreira Org. São Paulo: IDEA, 2018.

LUNA, Francisco Vidal. Escravismo em São Paulo e Minas Gerais. / Francisco Vidal Luna, Iraci Del Nero Costa, Hebert S. Klein [Org]. São Paulo: EDUSP: Imprensa Oficial do Estado de São Paulo, 2009.

MAIA, Francisco Prestes. Os Melhoramentos de São Paulo. São Paulo: Sub-divisão Gráfica da Prefeitura do Município de São Paulo, 1945

MARX, Murillo. Nosso chão: do sagrado ao profano. Série Espaço \& Desenho. História da Urbanização. São Paulo: Editora da Universidade de São Paulo, 1989

PARÉS, Luís Nicolau. A formação do candomblé. História e ritual da nação jeje na Bahia. São Paulo: Editora Unicamp, 2007.

QUINTÃO, Antônia Aparecida. Irmandades negras, outro espaço de luta e resistência (São Paulo, 1870-1890). - São Paulo: AnnaBlume/FAPESP, 2002.

REIS, Nestor Goulart. As Minas de Ouro e a formação das Capitanias do Sul. 1ạ. Edição. São Paulo: Via das Artes, 2013

RIBEIRO, Fabia Barbosa. Vivencias negras na cidade de São Paulo: entre territórios de exclusão e sociabilidade. Artigo. São Paulo: Projeto História, n. 57, pp. 108-138, Set.-Dez. 2016.

SANTOS, Carlos José Ferreira dos. Nem tudo era italiano. São Paulo e pobreza (1890-1915). 3ạ Edição. São Paulo: Editora Annablume/FAPESP, 2008.

SOUZA, Ney de. Catolicismo em São Paulo: 450 anos de presença da Igreja Católica em São Paulo. São Paulo: Editora Paulinas, 2004.

TIRAPELLI, Percival. Arquitetura e urbanismo no Vale do Paraíba: do colonial ao eclético. 1. ed. - São Paulo: Editora UNESP/ Edições Sesc São Paulo, 2014.

VIDE, Sebastião Monteiro da. Constituições Primeiras do Arcebispado da Bahia / feitas e ordenadas pelo ilustríssimo e reverendíssimo D. Sebastião Monteiro da Vide. Brasília: Senado federal, Conselho Editorial, 2007 